\title{
Topographic differentiations of biological soil crusts and hydraulic properties in fixed sand dunes, Tengger Desert
}

\author{
ZhiShan ZHANG ${ }^{1,2^{*}}$, YongLe CHEN ${ }^{1,2}$, BinXing XU ${ }^{1,2}$, Lei HUANG ${ }^{1,2}$, HuiJuan TAN ${ }^{1,2}$, XueJun DONG ${ }^{3}$ \\ ${ }^{1}$ Shapotou Desert Research and Experiment Station, Cold and Arid Regions Environmental and Engineering Research Institute, \\ Chinese Academy of Sciences, Lanzhou 730000, China; \\ ${ }^{2}$ Key Laboratory of Stress Physiology and Ecology in Cold and Arid Regions of Gansu Province, Lanzhou 730000, China; \\ ${ }^{3}$ Texas A\&M AgriLife Research and Extension Center at Uvalde, Uvalde TX 78801, USA
}

\begin{abstract}
Biological soil crusts (BSCs) play an important role in surface soil hydrology. Soils dominated with moss BSCs may have higher infiltration rates than those dominated with cyanobacteria or algal BSCs. However, it is unnown whether improved infiltration in moss BSCs is accompanied by an increase in soil hydraulic conductivity or water retention capacity. We investigated this question in the Tengger Desert, where a 43-year-old revegetation program has promoted the formation of two distinct types of BSCs along topographic positions, i.e. the moss-dominated BSCs on the interdune land and windward slopes of the fixed sand dunes, and the algal-dominated BSCs on the crest and leeward slopes. Soil water retention capacity and hydraulic conductivity were measured using an indoor evaporation method and a field infiltration method. And the results were fitted to the van Genuchten-Mualem model. Unsaturated hydraulic conductivities under greater water pressure $(<-0.01 \mathrm{MPa})$ and water retention capacities in the entire pressure head range were higher for both crust types than for bare sand. However, saturated and unsaturated hydraulic conductivities in the near-saturation range $(>-0.01 \mathrm{MPa})$ showed decreasing trends from bare sand to moss crusts and to algal crusts. Our data suggested that topographic differentiation of BSCs significantly affected not only soil water retention and hydraulic conductivities, but also the overall hydrology of the fixed sand dunes at a landscape scale, as seen in the reduction and spatial variability in deep soil water storage.
\end{abstract}

Keywords: algal crusts; hydraulic conductivity; moss crusts; soil water retention curve; Tengger Desert

Citation: ZhiShan ZHANG, YongLe CHEN, BinXing XU, Lei HUANG, HuiJuan TAN, XueJun DONG. 2015. Topographic differentiations of biological soil crusts and hydraulic properties in fixed sand dunes, Tengger Desert. Journal of Arid Land, 7(2): 205-215. doi: 10.1007/s40333-014-0048-y

Biological soil crusts (BSCs) are formed by close association between surface soil particles and cyanobacteria, algae, micro-fungi, lichen and bryophytes in different proportions (West, 1990; Li et al., 2004; Zhang et al., 2010). They are a critical component of desert ecosystems that improve soil fertility and stability, as well as affect many basic hydrological processes such as infiltration, runoff and soil water storage (Eldridge et al., 2000, 2002; Warren, 2003; Belnap, 2006). It has been shown that soils dominated with moss BSCs may have better infiltration (and thus reduced runoff) than those dominated by cyanobacterial or algal BSCs
(Brotherson and Rushforth, 1983; Maestre et al., 2002; Kidron et al., 2003; Eldridge et al., 2010). Soil texture has been shown to be especially important and could override many other factors influencing soil hydrological processes (Williams et al., 1999). Warren (2003) summarized that overall, BSCs decreased water infiltration in sandy soils (greater than 66\% sand) and increased infiltration where clays exceeded $15 \%$. Factors such as thickness and micro-relief of BSCs, even levels of crustal development could also affect infiltration and runoff (Belnap, 2006; Kidron, 2007; Malam et al., 2009; Almog and Yair, 2007).

"Corresponding author: ZhiShan ZHANG (E-mail: zszhang@lzb.ac.cn) Received 2014-06-04; revised 2014-11-11; accepted 2014-11-17

(c) Xinjiang Institute of Ecology and Geography, Chinese Academy of Sciences, Science Press and Springer-Verlag Berlin Heidelberg 2015 
Few studies on the effects of BSCs on hydrological processes have a central focus on soil hydraulic properties, although a few parameters, such as saturated hydraulic conductivity, have been considered (Williams et al., 1999; Eldridge et al., 2000, 2002). In particular, it is not known whether higher soil water infiltration rates associated with the moss-type BSCs is accompanied with the enhancements in both saturated and unsaturated soil hydraulic conductivities, and/or water retention capacity. Yet, both water retention capacity and soil hydraulic conductivity could reflect various soil physical and hydrological properties, such as soil texture, porosity, sorptivity and bulk density (van Genuchten, 1980; Halbertsma and Veerman, 1997), all of which affect the hydrological functions of BSCs (Belnap, 2006; Malam et al., 2009). Data of these hydraulic parameters are essential in the application of various hydrologic and erosion models describing water flows in the soil-plant system (Šimûnek et al., 1998; Williams et al., 1999; Hu et al., 2009). Finally, studies from different regions show that the hydraulic properties of BSCs are complex and highly site-specific (Williams et al., 1999; Wang et al., 2007a). As most of the current studies were conducted in hot deserts (Warren, 2003), data on soil hydraulic properties from cool or cold deserts are needed in order to investigate the relationships between BSCs and hydrological processes in these regions (Belnap, 2006).

In the Tengger Desert of northwestern China, the cold and dry Siberian-Mongolian high pressure system brings about the prevailing wind from the northwest to the southeast direction and forms the pattern of sand dune chains, dominated by interdune, windward, crest, leeward topographic positions (Shapotou Desert Research and Experiment Station, 1991). After 40 years of revegetation, moss crusts dominate on interdune land and windward slope of fixed sand dunes, while algal crusts are mainly distributed on the crest and leeward slopes ( $\mathrm{Li}$ et al., 2005, 2010; Su et al., 2007). Former studies showed that the BSCs formed in the sand-fixed area can intercept and retain most rainwater in soil surface and result in the reduction of deep soil water and retreat of perennial shrubs ( $\mathrm{Li}$ et al., 2004, 2011, 2014). However, there is no information on how the topographic distributions of
BSCs on fixed sand dunes impact hydrological and ecological processes, which is the focus of this paper. We hypothesized firstly that moss crusts have a higher hydraulic conductivity than algal crusts. Many studies on other deserts found that the presence of polysaccharides sheath in algal crusts could reduce infiltration and induce runoff (Eldridge et al., 2000, 2002, 2010; Maestre et al., 2002; Kidron et al., 2003; Almog and Yair, 2007; Malam et al., 2009), while moss crusts had an opposite effect on infiltration and runoff due to relatively low ratio of exopolysaccharides, higher surface roughness and enhanced macroporosity (Maestre et al., 2002; Kidron et al., 2003; Eldridge et al., 2010). Besides, the leeward side of a dune that is covered mainly by algal crusts has a steeper slope than the moss crusts-dominated windward side (Shapotou Desert Research and Experiment Station, 1991). Then, we further hypothesized that the topographic differentiations of BSCs and surface soil hydraulic properties exercise a strong effect on various hydrological processes. We had expected that runoff would be more easily generated on the leeward side than the windward side during rainstorms due to the steepness of the former site, which would result in differences in soil water content and plant distribution on different topographic positions.

The fixed sand dunes revegetated in 1964 in the Tengger Desert were used as the experimental site and an adjacent moving sand dune was taken as a control site. We hoped to (1) quantitatively describe the topographic differentiations of BSCs in fixed sand dunes; (2) investigate whether the soil hydraulic properties was enhanced due to the moss-dominated BSCs, as compared with the algal-dominated BSCs in the Tengger Desert; and (3) research whether the topographic differentiations of BSCs induce significant hydrological and ecological changes across the sand dune landscape.

\section{Materials and methods}

\subsection{Study area}

The experiment was conducted at the Shapotou Desert Research and Experiment Station (Conveniently abbreviated as Shapotou Station), Chinese Academy of Sciences. Shapotou Station is located at the southeast- 
ern edge of the Tengger Desert $\left(37^{\circ} 32^{\prime} \mathrm{N}, 105^{\circ} 02^{\prime} \mathrm{E}\right.$; $1,330 \mathrm{~m}$ asl). The sand dunes are made up of reticulated chains of barchan dunes and are inclined from northwest to southeast, representing the step distribution, with the relative height difference of 15-20 m. The dunes include four landscape types, i.e. the crests of dunes with a length of 10-20 m, the interdune depressions with a length of 10-30 m, the north- or northwest-facing windward that has long and gentle slope with a length of $50-80 \mathrm{~m}$, and the south- or southeast-facing leeward that has short and steep slope with a length of 20-30 m (Shapotou Desert Research and Experiment Station, 1991). In this region, the main soils are Orthic Sierozem and aeolian sandy soil (FAO/UNESCO, 1974), with a low water retention capacity (Li et al., 2004). The ground water level is deep (about $-80 \mathrm{~m}$ ) and cannot be tapped by plant roots (Berndtsson and Chen, 1994). Natural vegetation in the dunes is dominated by Hedysarum scoparium Fisch. \& C. A. May. and Agriophyllum squarrosum Moq., with vegetation cover of around 1\%. Annual mean temperature is $9.6^{\circ} \mathrm{C}$, with the maximum temperature of $38.1^{\circ} \mathrm{C}$ and the minimum temperature of $-25.1^{\circ} \mathrm{C}$. In this area, precipitation is the only source of soil water available to plants. Average annual precipitation is $186 \mathrm{~mm}$, and precipitation is uneven through a year, occurring mainly from July through September. Mean air relative humidity is $40 \%$, with the lowest value of $10 \%$.

For stabilizing the migrating sand dunes, rows of straw in a checkerboard pattern with $1 \mathrm{~m} \times 1 \mathrm{~m}$ squares were first established by inserting straw vertically into the soil to a depth of $0.15-0.20 \mathrm{~m}$, so that it protruded approximately $0.10-0.15 \mathrm{~m}$ above the dune surface. The straw checkerboard structures remained intact for four to five years. Xerophytic shrubs (e.g. Salix gordejevii Chang, Calligonum arborescens Litv., Atraphaxis bracteata Losinsk., Caragana korshinskii Kom., Artemisia ordosica Krasch. and H. scoparium) were then planted in the straw checkerboard plots starting in 1956 along the Baotou-Lanzhou railway, which form a restored vegetation belt.

These rehabilitation methods have promoted the deposition of air-borne dust onto the dune surface, and as more and more microorganisms accumulated, BSCs developed ( $\mathrm{Li}$ et al., 2005). In 40 years, two types of crusts dominate the study site, i.e. moss and algal. Moss crusts composed primarily of Bryum argenteum Hedw. and Didymodon constrictus (Mitt.) Saito. occur mainly at windward slope and interdune land on the dunes. Algal crusts, composed mainly of filamentous cyanobacteria (accounting for 46\%), green algae (18\%), diatom (27\%), and Euglena sp. (9\%), appear dominantly on the crest and leeward slopes of the dunes (Li et al., 2005, 2010; Su et al., 2007).

\subsection{Soil and plant investigation}

In 2007, sampling was conducted at four topographic positions, i.e. crest, interdune land, windward and leeward slopes of six fixed sand dunes revegetated in 1964 and six moving sand dunes. Moss and algal crust cover was determined using an 11-point sampling frame of $0.1 \mathrm{~m} \times 0.1 \mathrm{~m}$ (totaling 121 points), similar to the device described by Li et al. (2010). In each topographic position, twelve random measurements were carried out after rainfall. Also, BSCs thickness was measured in pits dug to a depth of about $10 \mathrm{~cm}$ after rainfall, and intact surface soil samples were taken to measure bulk density by drying the samples at $105^{\circ} \mathrm{C}$ for 48 hours. These samples were taken from each of the four topographic positions and replicated 12 times. Also, at each topographic position, twelve shrub quadrats $(10 \mathrm{~m} \times 10 \mathrm{~m})$ and 36 quadrats for annual species $(1 \mathrm{~m} \times 1 \mathrm{~m})$ were set up to investigate vegetation density and cover in September, 2007.

Eighteen soil samples from each topographic position were collected at depths of $0-0.05,0.05-0.1$ and 0.1-0.2 m. Three samples from each layer were combined for physical and chemical properties analysis, totally six composite samples were created from each layer. Soil particle size was analyzed using an MS-S light scattering apparatus (Malvern Instruments, Malvern, UK); $\mathrm{pH}$ was measured in water (soil:water ratio=1:5); soil organic carbon was determined by the $\mathrm{K}_{2} \mathrm{Cr}_{2} \mathrm{O}_{7}$ method; and total nitrogen was determined with the Kjeltec System 1026 Distilling Unit (Tecator AB, Sweden) ( Li et al., 2010).

To differentiate topographic effect on soil water contents, in June of 2007, soil samples from the 0-3 m soil profile were taken by soil auger in each position on both fixed sand dunes and moving sand dunes at 10 
$\mathrm{cm}$ intervals in the upper $40 \mathrm{~cm}$ layer, and at $20 \mathrm{~cm}$ intervals below a depth of $40 \mathrm{~cm}$, with six replications per depth. Soil samples were dried at $105^{\circ} \mathrm{C}$ for 48 hours to measure gravitational soil water content. Through transformation using bulk density, volumetric soil water content was obtained.

\subsection{Determination of soil hydraulic properties}

The intact soil samples were collected using a PVC cylinder $(100-\mathrm{mm}$ in inner diameter and $80-\mathrm{mm}$ in height) with four preset holes on its side wall located 10, 30, 50 and $70 \mathrm{~mm}$ from the top for the installation of tensiometers. Two soil samples were taken on a windward slope dominated by moss crusts (located at upper and lower sides on windward, respectively), one of the algal crust samples was taken on a crest and another was taken on a leeward slope. Considering the complete uniform soil properties of the moving sand dune, only one sample was collected on the windward slope of the moving sand dune without vegetation as control. Samples at interdune lands were not collected due to the similarities in surface properties to those of the windward slope. After taking the sample into the laboratory, the sampling cylinder was saturated with distilled water in the exsiccator (slight vacuum around $<23 \mathrm{KPa}$ ) by placing lower part of the sample into water for 48 hours, during which water was added three times up to the top of the PVC cylinder, then covered with a lid and set aside for at least 24 hours to drain the water. Then, the bottom lid was attached, and four tensiometers (outer diameter is $6 \mathrm{~mm}$, length $55 \mathrm{~mm}$ ) filled with distilled water and connected to a pressure transducer unit, were inserted horizontally into pre-bored holes. Relationships between soil water potential $(h)$, water content $(\theta)$ and hydraulic conductivity $(K)$ were determined using the Star-1 Evaporating Measurement System (SC-DLO, Wageningen, Netherlands). The soil sample was placed on a digital balance (with precision to the nearest $0.1 \mathrm{~g}$ ) and the four tensiometers were connected to a pressure transducer. Automatic sampling of soil water pressure and weighing of the sample were completed at one hour interval. The detailed methods are described by Halbertsma and Veerman (1997). The experiment continued until all four tensiometers were 'broken down', i.e. when air entered the ceramic tensiometers. Finally, the soil was removed from the PVC cylinder, weighed and dried at $105^{\circ} \mathrm{C}$ for 48 hours to calculate saturated water content $\left(\theta_{s}\right)$ and residual water content $\left(\theta_{r}\right)$.

The evaporation method usually fails in the near-saturation range where the hydraulic conductivity is the highest, leading to very small hydraulic gradients that cannot be determined with sufficient accuracy (Šimûnek et al., 1998). Therefore, unsaturated soil hydraulic conductivities close to saturation at pressure heads of -1 and $-10 \mathrm{~cm}$ (i.e. soil water potential is $-9.8 \times 10^{-5}$ and $\left.-9.8 \times 10^{-4} \mathrm{Mpa}\right)$ were determined in-situ using the tension disc infiltrometer (model 2826D20, Soil-moisture Equipment Corp., CA, USA). Six places were selected at each of the five positions where intact soil samples were previously taken. A fine sand bed of about $20 \mathrm{~mm}$ deep was placed on the soil surface at the revegetated dune to ensure good contact between the tension disc and the soil.

The data from both the evaporation and infiltration sampling were analyzed using the computer program Appia 2.0 for Windows (Group Software Engineering/Soil Physical Laboratory, SC-DLO Wageningen, Netherlands, April 1998), which performed iterative calculations and generated the $h-\theta-K$ dataset (Halbertsma and Veerman, 1997) and the closed-form equations of van Genuchten (1980) and Mualem (1976). This method was similar to the optimization method described by Šimûnek et al. (1998) and produced the optimized saturated soil hydraulic conductivity $(K s)$ and the curve shape parameters ( $\alpha$ and $n$ ).

\subsection{Data analysis}

Data were log-transformed prior to analysis to ensure that they met the normal distribution requirements if necessary. All data from revegetated dunes and moving sand dunes were analyzed using two-way ANOVA with revegetation or no and "topographic position” as dependent variables, and compared least significant differences at $P<0.05$ level using the Tukey post hoc test when equal variance occurred and Tamhane's T2 test when equal variance did not satisfy. Statistical analyses and graphic plotting were conducted using SPSS 13.0 and Origin 7.0 , respectively. 


\section{Results}

\subsection{BSCs and plant characteristics}

There were no BSCs and little vegetation on moving sand dunes and also no significantly topographic differences. However, these BSCs and plant characteristics except for soil bulk densities were significantly different from those at fixed sand dunes using two-way ANOVA. The stabilization of moving sand dunes with straw checkerboards and revegetation has resulted in the formation and development of BSCs at the soil surface. After 43 years, BSCs covered almost all fixed sand dunes' surface, and two types of BSCs were associated with the different topographic types (Table 1). On windward slope and interdune land of fixed sand dunes, moss crusts inhabited about $80 \%$ of the soil surface, significantly higher than algal crusts cover (11.5\% to $22.5 \%)$. However, on the leeward slope and crest of fixed sand dunes, algal crusts covered about $60 \%$ of the soil surface, significantly higher than moss crusts cover (about 10\%). Total BSCs covers on windward and interdune sites of fixed sand dunes were $89.9 \%$ and $92.9 \%$, respectively, significantly higher than those on leeward (72.4\%) and crest (78.9\%). BSC thickness on crest, windward and interdune of fixed sand dunes appeared to increase (in that order), but showed no significant difference with an average $35.5 \mathrm{~mm}$. Crust thickness on leeward slopes with an average of $23.2 \mathrm{~mm}$ was significantly lower than those on other positions. Bulk densities on the four topographic positions showed no significant difference (average of $1.44 \times 10^{3} \mathrm{~kg} / \mathrm{m}^{3}$ ), but they were obviously less than those on moving sand dunes $\left(1.59 \times 10^{3} \mathrm{~kg} / \mathrm{m}^{3}\right)$ (Table 1$)$.

Table 1 Field investigation of cryptogamic cover and thickness of biological soil crusts and bulk densities, densities and cover of annuals and shrubs in four topographic positions on fixed sand dunes revegetated in 1964 and on the moving sand dunes (MSDs)

\begin{tabular}{lcccccc}
\hline \multicolumn{1}{c}{ Index } & MSDs & Crest & Windward & Interdune & Leeward & $\mathrm{N}$ \\
\hline Moss cover (\%) & 0 & $22.5 \pm 3.7^{\mathrm{b}}$ & $78.3 \pm 6.8^{\mathrm{a}}$ & $83.7 \pm 12.5^{\mathrm{a}}$ & $11.2 \pm 8.9^{\mathrm{b}}$ & 12 \\
Algae cover (\%) & 0 & $56.4 \pm 8.9^{\mathrm{a}}$ & $11.6 \pm 2.4^{\mathrm{b}}$ & $9.2 \pm 4.3^{\mathrm{b}}$ & $61.2 \pm 10.3^{\mathrm{a}}$ & 12 \\
Thickness of crusts (mm) & 0 & $30.6 \pm 6.3^{\mathrm{b}}$ & $36.9 \pm 10.0^{\mathrm{ab}}$ & $38.9 \pm 5.4^{\mathrm{a}}$ & $23.2 \pm 6.3^{\mathrm{c}}$ & 12 \\
Bulk density $\left(10^{3} \mathrm{~kg} / \mathrm{m}^{3}\right)$ & $1.59 \pm 0.04$ & $1.43 \pm 0.08^{\mathrm{a}}$ & $1.45 \pm 0.13^{\mathrm{a}}$ & $1.41 \pm 0.12^{\mathrm{a}}$ & $1.47 \pm 0.18^{\mathrm{a}}$ & 12 \\
Annuals density (plants $\left./ \mathrm{m}^{2}\right)$ & $<1$ & $138.9 \pm 18.8^{\mathrm{b}}$ & $163.5 \pm 18.6^{\mathrm{a}}$ & $162.6 \pm 28.9^{\mathrm{a}}$ & $127.9 \pm 22.2^{\mathrm{b}}$ & 36 \\
Annuals cover (\%) & $<1$ & $20.8 \pm 5.7^{\mathrm{ab}}$ & $25.3 \pm 1.2^{\mathrm{a}}$ & $27.5 \pm 4.7^{\mathrm{a}}$ & $12.5 \pm 2.4^{\mathrm{b}}$ & 36 \\
Shrubs density (plants $\left./ 100 \mathrm{~m}^{2}\right)$ & $<1$ & $10.8 \pm 2.3^{\mathrm{bc}}$ & $15.0 \pm 2.8^{\mathrm{b}}$ & $23.6 \pm 4.7^{\mathrm{a}}$ & $9.1 \pm 1.8^{\mathrm{c}}$ & 12 \\
Shrubs cover (\%) & $<1$ & $7.8 \pm 3.7^{\mathrm{b}}$ & $8.7 \pm 3.3^{\mathrm{ab}}$ & $12.0 \pm 3.6^{\mathrm{a}}$ & $6.7 \pm 5.3^{\mathrm{b}}$ & 12 \\
\hline
\end{tabular}

Note: Differences caused by the effects of topographic types were determined using two-way ANOVA, excluding data from the moving sand dunes due to marked differences as compared to revegetated areas. Different letters in same row indicate significant differences at $P<0.05$ level. $\mathrm{N}$, the number of samples. Data shown as mean \pm SE.

We found that density and cover of annuals and shrubs on the four topographic positions of fixed sand dunes showed significant differences. Vegetation density on windward slope and interdune land of fixed sand dunes was 163 plants $/ \mathrm{m}^{2}$, obviously higher than those on leeward and crest (127.9 and 138.9 plants $/ \mathrm{m}^{2}$, respectively). Annual plants' covers on the windward and interdune of fixed sand dunes were $25.3 \%$ and $27.5 \%$, respectively, higher than the $20.8 \%$ on the crest and significantly higher than $12.5 \%$ on the leeward. Shrub density and cover were the highest on the interdune (23.6 plants/100 $\mathrm{m}^{2}$ and $12 \%$, respectively), followed in the order of windward, crest and leeward for both variables (Table 1).

\subsection{Soil physical and chemical properties}

Similar to BSCs and vegetation, soil properties of moving sand dunes had no significantly topographic differences although they were obviously different from those of fixed sand dunes. Formations of BSCs on fixed sand dunes were always concomitant with the improvement of soil physical and chemical properties. Likewise, the soil physical and chemical properties showed topographic differentiations (Table 2). Interdune areas of fixed sand dunes had the least sand content $(51.85 \%)$ and the highest silt and clay contents (42.02\% and $6.13 \%$, respectively) in the $0-0.05 \mathrm{~m}$ soil layer. Values for the windward and crest were similar, but the leeward had the highest sand content with 
65.66\% and the least silt and clay contents with $30.15 \%$ and $4.19 \%$, respectively. Similar trends also occurred in the $0.05-0.1$ and $0.1-0.2 \mathrm{~m}$ soil layers. Interdune areas had $\mathrm{pH}$ of 7.30 in the $0-0.05 \mathrm{~m}$ soil layer, significantly lower than those on other topographic types, but $\mathrm{pH}$ in the deeper layers showed no obvious topographic differences. Fine particles enriched fixed sand dunes and increased organic carbon and total nitrogen contents. Organic carbon contents amounted to $11.57 \mathrm{~g} / \mathrm{kg}$ in the
0-0.05 m layer and $5.38 \mathrm{~g} / \mathrm{kg}$ in the $0.05-0.1 \mathrm{~m}$ layer of the interdune areas were the highest, followed by those of the windward and crest, and the least for that of leeward, but organic carbon contents of different topographic sites had no markedly differences in the 0.1-0.2 $\mathrm{m}$ layer. However, total nitrogen contents at all three layers on the interdune of fixed sand dunes were significantly higher than those on other topographic positions.

Table 2 Physical and chemical properties of three soil layers at four topographic positions of fixed sand dunes revegetated in 1964 and on the moving sand dunes (MSDs)

\begin{tabular}{|c|c|c|c|c|c|c|}
\hline & Soil layer (m) & MSDs & Crest & Windward & Interdune & Leeward \\
\hline \multirow{3}{*}{ Sand (\%) } & $0-0.05$ & $99.12 \pm 0.24$ & $58.42 \pm 2.01^{\mathrm{b}}$ & $55.15 \pm 1.57^{\mathrm{ab}}$ & $51.85 \pm 1.82^{\mathrm{a}}$ & $65.66 \pm 2.32^{c}$ \\
\hline & $0.05-0.1$ & $99.30 \pm 0.32$ & $79.10 \pm 1.84^{b}$ & $80.09 \pm 1.42^{\mathrm{b}}$ & $64.38 \pm 1.31^{\mathrm{a}}$ & $80.28 \pm 1.94^{b}$ \\
\hline & $0.1-0.2$ & $99.39 \pm 0.21$ & $98.11 \pm 0.42^{\mathrm{a}}$ & $97.79 \pm 0.35^{\mathrm{a}}$ & $95.04 \pm 0.40^{\mathrm{a}}$ & $97.72 \pm 0.63^{\mathrm{a}}$ \\
\hline \multirow{3}{*}{ Silt (\%) } & 0-0.05 & $0.88 \pm 0.08$ & $35.28 \pm 1.68^{\mathrm{b}}$ & $38.82 \pm 1.85^{\mathrm{bc}}$ & $42.02 \pm 1.76^{\mathrm{c}}$ & $30.15 \pm 1.85^{\mathrm{a}}$ \\
\hline & $0.05-0.1$ & $0.14 \pm 0.03$ & $17.91 \pm 0.79^{\mathrm{a}}$ & $16.86 \pm 1.36^{\mathrm{a}}$ & $31.20 \pm 1.07^{\mathrm{b}}$ & $16.96 \pm 0.94^{\mathrm{a}}$ \\
\hline & $0.1-0.2$ & $0.09 \pm 0.01$ & $1.22 \pm 0.17^{\mathrm{a}}$ & $1.34 \pm 0.28^{\mathrm{a}}$ & $3.88 \pm 0.17^{\mathrm{b}}$ & $1.61 \pm 0.26^{\mathrm{a}}$ \\
\hline \multirow{3}{*}{ Clay (\%) } & $0-0.05$ & $0.00 \pm 0.00$ & $6.30 \pm 0.65^{\mathrm{b}}$ & $6.03 \pm 0.83^{\mathrm{b}}$ & $6.13 \pm 0.74^{\mathrm{b}}$ & $4.19 \pm 0.71^{\mathrm{a}}$ \\
\hline & $0.05-0.1$ & $0.56 \pm 0.36$ & $2.99 \pm 0.32^{\mathrm{a}}$ & $3.05 \pm 0.68^{\mathrm{a}}$ & $4.42 \pm 0.47^{b}$ & $2.76 \pm 0.37^{\mathrm{a}}$ \\
\hline & $0.1-0.2$ & $0.53 \pm 0.28$ & $0.67 \pm 0.04^{\mathrm{a}}$ & $0.87 \pm 0.14^{\mathrm{a}}$ & $1.09 \pm 0.24^{\mathrm{a}}$ & $0.67 \pm 0.16^{a}$ \\
\hline \multirow{3}{*}{$\mathrm{pH}$} & 0-0.05 & $8.10 \pm 0.27$ & $7.90 \pm 0.17^{\mathrm{b}}$ & $7.73 \pm 0.06^{\mathrm{b}}$ & $7.30 \pm 0.04^{\mathrm{a}}$ & $7.68 \pm 0.08^{\mathrm{b}}$ \\
\hline & $0.05-0.1$ & $8.17 \pm 0.08$ & $8.19 \pm 0.13^{\mathrm{a}}$ & $8.19 \pm 0.02^{\mathrm{a}}$ & $7.98 \pm 0.07^{\mathrm{a}}$ & $8.10 \pm 0.05^{\mathrm{a}}$ \\
\hline & $0.1-0.2$ & $8.07 \pm 0.12$ & $8.18 \pm 0.18^{\mathrm{a}}$ & $8.23 \pm 0.21^{\mathrm{a}}$ & $8.18 \pm 0.08^{\mathrm{a}}$ & $8.15 \pm 0.11^{\mathrm{a}}$ \\
\hline \multirow{3}{*}{$\begin{array}{c}\text { Organic car- } \\
\text { bon (g/kg) }\end{array}$} & $0-0.05$ & $0.80 \pm 0.45$ & $9.69 \pm 0.72^{\mathrm{b}}$ & $10.99 \pm 0.57^{\text {bc }}$ & $11.57 \pm 0.38^{c}$ & $7.19 \pm 0.86^{\mathrm{a}}$ \\
\hline & $0.05-0.1$ & $1.60 \pm 0.28$ & $3.79 \pm 0.29^{b}$ & $2.99 \pm 0.88^{\mathrm{a}}$ & $5.38 \pm 0.52^{c}$ & $3.18 \pm 0.67^{\mathrm{a}}$ \\
\hline & $0.1-0.2$ & $1.76 \pm 0.30$ & $3.09 \pm 0.34^{\mathrm{a}}$ & $2.99 \pm 0.85^{\mathrm{a}}$ & $2.89 \pm 0.34^{\mathrm{a}}$ & $2.69 \pm 0.42^{\mathrm{a}}$ \\
\hline \multirow{3}{*}{$\begin{array}{l}\text { Total nitrogen } \\
(\mathrm{g} / \mathrm{kg})\end{array}$} & $0-0.05$ & $0.007 \pm 0.008$ & $0.255 \pm 0.056^{\mathrm{a}}$ & $0.221 \pm 0.048^{\mathrm{a}}$ & $0.393 \pm 0.029^{b}$ & $0.238 \pm 0.038^{a}$ \\
\hline & $0.05-0.1$ & $0.016 \pm 0.007$ & $0.121 \pm 0.028^{\mathrm{a}}$ & $0.120 \pm 0.037^{\mathrm{a}}$ & $0.289 \pm 0.017^{b}$ & $0.100 \pm 0.007^{\mathrm{a}}$ \\
\hline & $0.1-0.2$ & $0.011 \pm 0.004$ & $0.098 \pm 0.031^{\mathrm{a}}$ & $0.089 \pm 0.022^{\mathrm{a}}$ & $0.180 \pm 0.024^{b}$ & $0.084 \pm 0.027^{a}$ \\
\hline
\end{tabular}

Note: Two-way ANOVA was used to differentiate the effects of landscape types, except for moving sand dunes due to marked differences as compared to revegetated areas. Different letters in same row indicate significant differences at $P<0.05$ level. Data shown as mean \pm SE.

\subsection{Surface soil hydraulic properties}

With formation of BSCs and improvement of soil physical/chemical properties on fixed sand dunes, the changes in soil hydraulic properties occurred. Based on the data measured by the indoor evaporation and field infiltration methods, we fitted soil water retention and soil hydraulic conductivity functions. As an example, moss crusts dominated the windward slope of the fixed sand dune (Fig. 1). Matched curves using the van Genuchten and Mualem model are shown in Fig. 2 and the optimized parameters are listed in Table 3. Samples from windward slopes dominated by moss crusts had the highest saturated soil water contents $(\theta s)$ (averaging $0.376 \mathrm{~m}^{3} / \mathrm{m}^{3}$ ) and the lowest shape parameters $\alpha$ and $n$ ( 0.167 and 2.148, respectively). Like values from the crest dominated by algal crusts averaged $0.359 \mathrm{~m}^{3} / \mathrm{m}^{3}$ and 0.172 and 3.433 , respectively. This is in contrast to samples from the moving sand dune, which had the lowest $\theta_{s}$ and the highest $\alpha$ and $n$. While the soil of moving sand dunes had the highest saturated hydraulic conductivity $\left(K_{s}\right)$ with 4.46 $\mathrm{m} / \mathrm{d}$, the $K_{s}$ value for the soil with moss crusts averaged $0.63 \mathrm{~m} / \mathrm{d}$, followed by the soil with algal crusts with an average of $0.39 \mathrm{~m} / \mathrm{d}$ (Table 3). Also, water retention capacities in the entire pressure head range showed an increasing trend from moving sand dunes to algal crusts, and to moss crusts. Unsaturated 

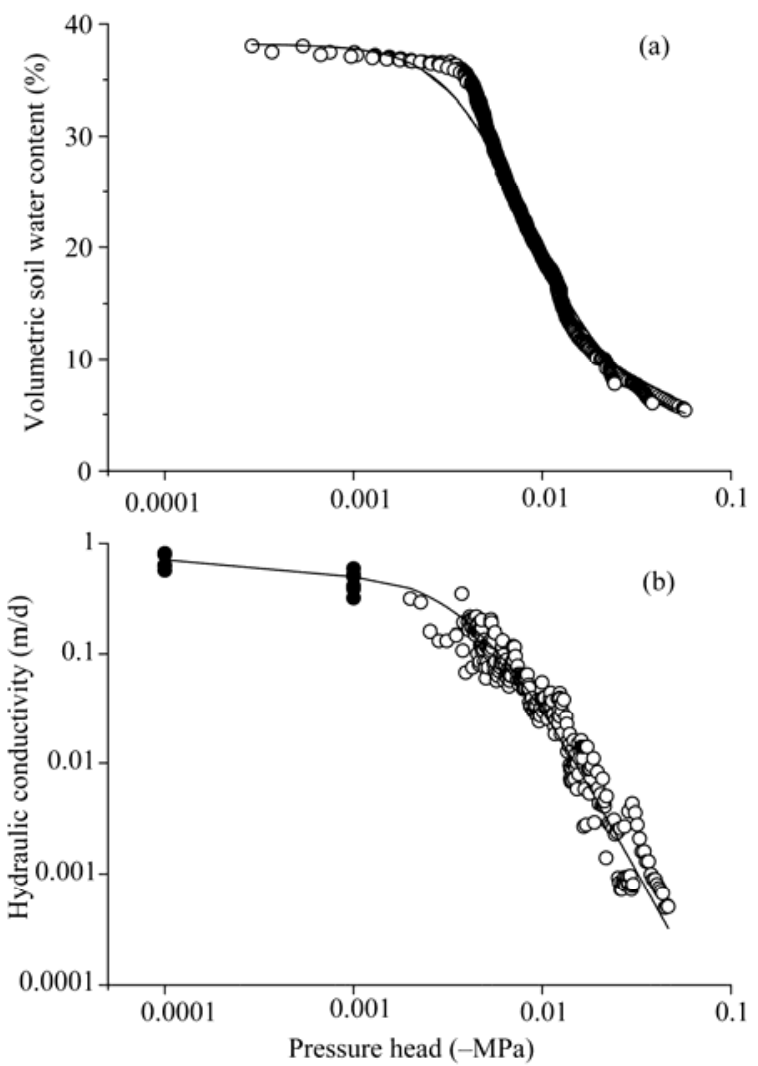

Fig. 1 Measured and fitted soil water retention (a) and hydraulic conductivity (b) on the windward slopes of fixed sand dunes revegetated in 1964 (dominated by moss crusts). Open symbols (०) represents the data observed with an indoor evaporation method, closed symbols $(\bullet)$ represents the data observed with a field infiltration method and lines represent fitted curves using the van Genuchten-Mualem model.

Table 3 Parameters of van Genuchten-Mualem model

\begin{tabular}{cccccc}
\hline Parameter & MSDs & Moss1 & Moss2 & Algae1 & Algae2 \\
\hline$\theta_{r}\left(\mathrm{~m}^{3} / \mathrm{m}^{3}\right)$ & 0.022 & 0.059 & 0.023 & 0.006 & 0.054 \\
$\theta_{s}\left(\mathrm{~m}^{3} / \mathrm{m}^{3}\right)$ & 0.333 & 0.370 & 0.382 & 0.362 & 0.355 \\
$\alpha$ & 0.018 & 0.017 & 0.017 & 0.017 & 0.017 \\
$n$ & 7.812 & 2.165 & 2.130 & 2.716 & 4.150 \\
$K_{s}(\mathrm{~m} / \mathrm{d})$ & 4.460 & 0.555 & 0.710 & 0.411 & 0.372 \\
$R^{2}$ & 0.813 & 0.915 & 0.791 & 0.784 & 0.950 \\
$N$ & 863 & 950 & 747 & 780 & 897
\end{tabular}

Note: $\theta_{r}$, residual water content; $\theta_{s}$, saturated water content; $\alpha$ and $n$ are suitable experienced parameters; $K_{s}$, saturated hydraulic conductivity; $R^{2}$, coefficient of determination; $N$, number of pairs of values $(h, \theta)$ to which a Van Genuchten curve was fitted. MSDs sampled on windward slope of moving sand dunes; Moss sampled from windward slopes of fixed sand dunes revegetated in 1964 and dominated by moss crusts; Algae sampled from crests of fixed sand dunes revegetated in 1964 and dominated with algal crusts; the number 1 and 2 refers to replications.

hydraulic conductivities on three sites had dramatic differences. In the near-saturation range $(>-0.01 \mathrm{MPa})$, unsaturated hydraulic conductivities of the soils showed a decreasing trend from moving sand dunes to moss crusts, and to algal crusts, and similar to Ks.
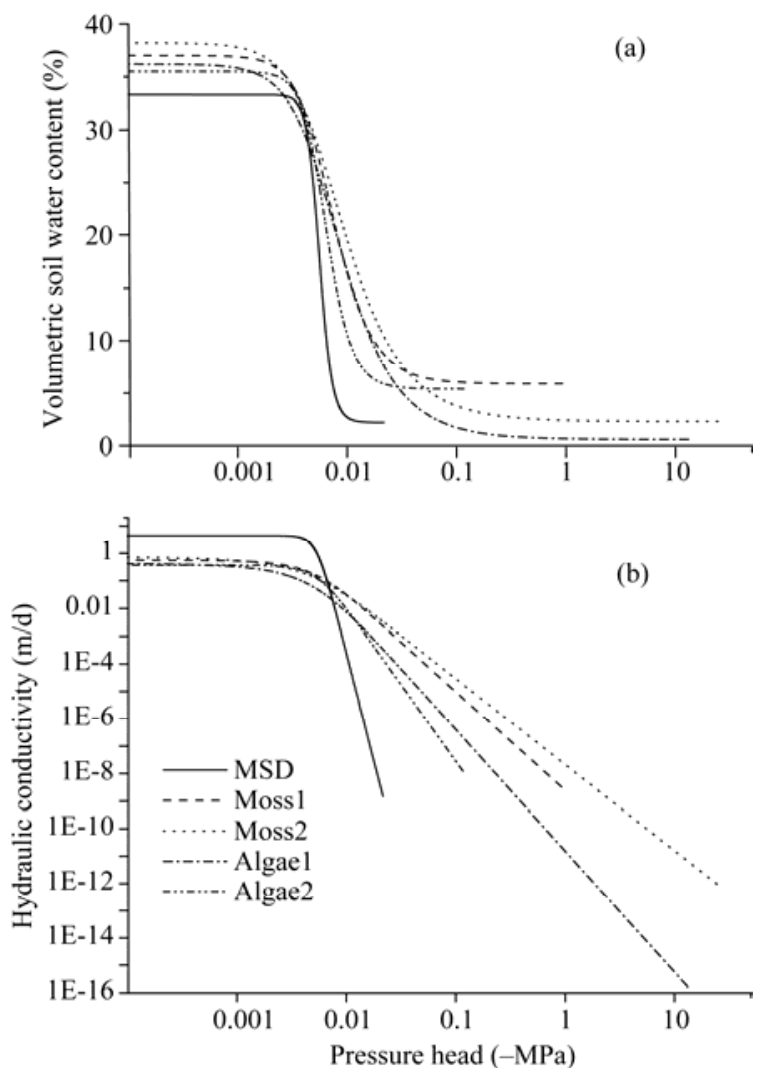

Fig. 2 Soil water retention curves (a) and hydraulic conductivity functions (b) fitted using the van Genuchten-Mualem model. MSDs, moving sand dunes; Moss, moss crusts on the windward slopes of fixed sand dunes revegetated in 1964; Algae, algal crusts on the crests of fixed sand dunes revegetated in 1964.

However, when the pressure heads were less than about $-0.01 \mathrm{MPa}$, the unsaturated hydraulic conductivities of the soil showed an increasing trend from the soil of moving sand dunes to algal crusts and to moss crusts (Fig. 2).

\subsection{Soil water contents}

Soil water contents in the $0-3 \mathrm{~m}$ soil depth at four topographic positions of fixed sand dunes and of moving sand dunes are shown in Fig. 3. For moving sand dunes, deep soil water content in the $0.4-3.0 \mathrm{~m}$ layer on interdune lands was significantly higher than those on other topographic positions ( $F=27.5, P<$ 0.001 ), but the deep soil water contents on the crest, windward and leeward slopes had no significant differences. For the fixed sand dunes revegetated in1964, deep volumetric soil water content in the $0.4-3.0 \mathrm{~m}$ layer averaged $1.6 \%$, which was lower than $3.6 \%$ of moving sand dunes. Similarly, there were significant 


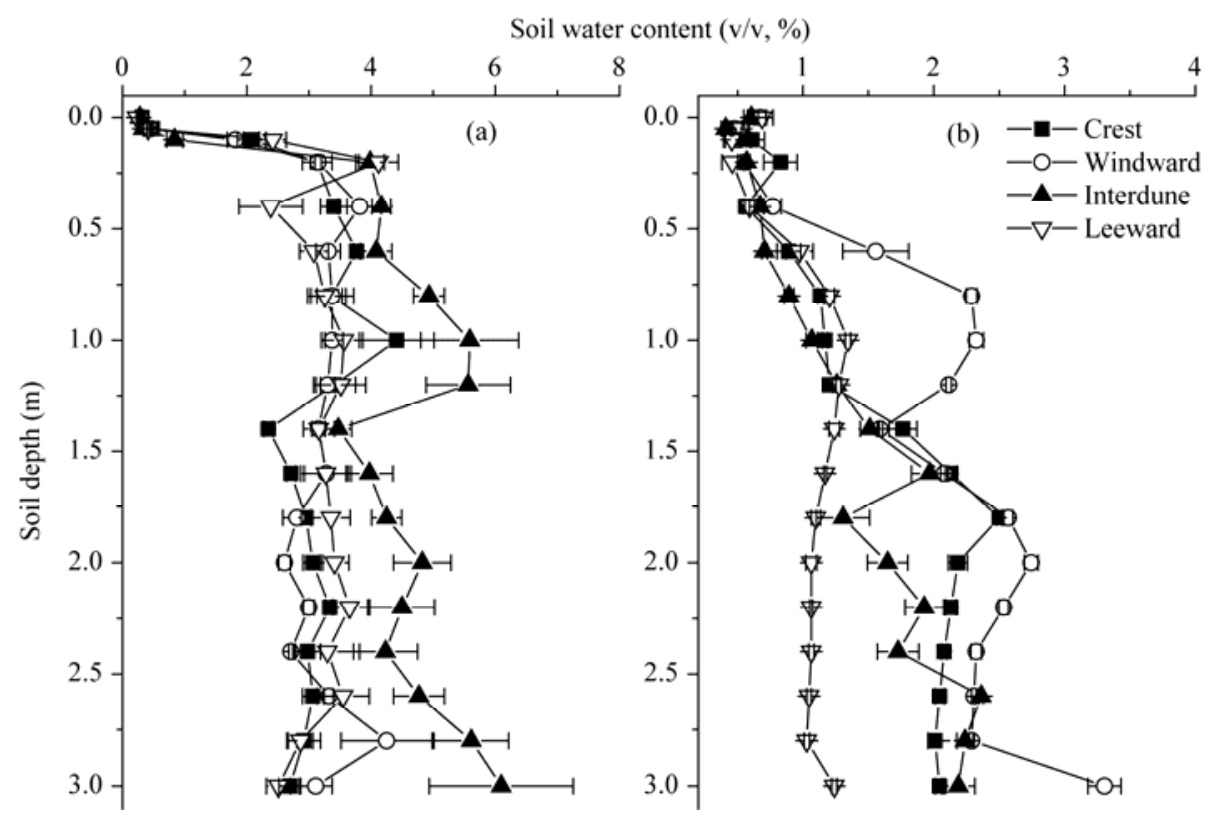

Fig. 3 Soil water contents in soil profiles of 0-3 $\mathrm{m}$ on four topographic positions (crest, interdune land, windward and leeward slopes) of moving sand dunes (a) and of fixed sand dunes revegetated in 1964 (b). Data are averages of six samples, with bars signifying standard error.

topographic differences $(F=12.4, P<0.001)$. Deep soil water contents below $0.4 \mathrm{~m}$ on the interdune were significantly higher than those on the leeward and crests, but were not significantly different from the windward (Tamhane's T2 test). Soil water contents in the 0.4-1.4 m depth layer of leeward slopes were significantly lower than those of the windward slopes and interdunes but had no significant difference when compared with the crests. Moreover, deep soil water contents below $1.4 \mathrm{~m}$ layer on the leeward slopes were the lowest and significantly lower than those at the other sites.

\section{Discussion}

Stabilization of moving sand dunes with straw checkerboards and revegetation in the Tengger Desert has lead to markedly higher vegetation density and cover than those moving sand dunes ( $\mathrm{Li}$ et al., 2004, 2010, 2011, 2014; Wang et al., 2007b; Zhang et al., 2008). This change has also resulted in topographic differentiations of surface soil hydraulic properties, which are mainly attributed to the differences in cover and composition of BSCs on different landscape types across fixed sand dunes. Our results verify earlier observations in which moss crusts are mainly distributed on windward slope and interdune land, and algal crusts dominated on leeward slopes and crests on 43-year-old fixed sand dunes (Li et al., 2005, 2010; Su et al., 2007).

Also, we found that in comparison with moving sand dunes, surface soil on fixed sand dunes showed higher water retention capacity and lower $\alpha, n, K s$ and unsaturated hydraulic conductivity in the near-saturation range, which may be attributed to the greater proportions of clay and silt contents and the higher organic carbon on fixed sand dunes (Duan et al., 2004; Wang et al., 2007a). However, sand, silt and clay contents and organic carbon were not significantly different between the windward and crest (Table 2), suggesting that the differences in water retention capacities and $\alpha, n$ and $K s$ between the two topographic positions could not be explained by soil physical and chemical properties. Nevertheless, there were significant differences in compositions of BSCs between windward slope and crest, dominated by moss crusts and algal crusts, respectively (Table 1). This strongly suggests that the topographic differentiations of water retention capacity, parameters $\alpha, n, K s$ and unsaturated hydraulic conductivity in the near-saturation range are mainly attributed to BSCs. 
Many studies have shown that cyanobacterial crusts have higher water retention capacity and lower $K s$ in comparison with bare soil because the filaments and polysaccharides of cyanobacteria rapidly swell during wetting and reduce the porosity of soil (Eldridge et al., 2000, 2002; George et al., 2003; Zhang et al., 2008; Malam et al., 2009;). The protonemata and rhizoids of moss in crusts are also able to absorb large amounts of water that induce a higher water retention capacity (Hu et al., 2002; Liu et al., 2007). Furthermore, their water-channeling properties help to maintain higher $K s$ and unsaturated hydraulic conductivity than cyanobacterial crusts in the near-saturation range (Kidron et al., 2003). Also, unsaturated hydraulic conductivity in the lower matric potential range $(<-0.01 \mathrm{MPa})$ showed an increasing trend from the soils of moving sand dunes to algal crusts, and to moss crusts, which may be due to increased numbers of microspores in the soils. The result is confirmed by $\theta s$ and shape parameter $n$, which can partly reflect soil porosity (van Genuchten, 1980; Šimûnek et al., 1998). However, our result contradicts the conclusion of Williams et al. (1999) that cyanobacterial-dominated crust in Utah, where soil has more clay and silt contents than our experimental site, had no discernible impact on hydraulic conductivity.

The topographic differentiations of BSCs and surface soil hydraulic properties have a profound impact on various hydrological processes. The results concur with conclusions from the earlier studies, i.e. the presence of BSCs in fixed sand dunes could reduce rainfall infiltration depth, result in greater dryness in the deep soil profile, and influence the succession of revegetation through the reduction in deep-rooted perennials and the proliferation of herbs ( $\mathrm{Li}$ et al., 2001; Li et al., 2004, 2010; Wang et al., 2006, 2007a, b). Moreover, the presence of BSCs in fixed sand dunes increases the heterogeneity of soil water storage. The interdune area stored more water than other sites, and the leeward slope had the lowest deep soil water contents, presumably due to the steep slope and the dominance of the algal crusts. This is also verified by the significant differences in soil physical and chemical properties between the leeward slope and interdune land (Table 2).

The effect of BSCs on deep soil water storage is closely related to infiltration and runoff. Earlier studies in the fixed sand dunes showed that presence of BSCs always reduce infiltration depth of rainfall when compared with moving sand dunes ( $\mathrm{Li}$ et al., 2001, 2004; Wang et al., 2007b). Our results further showed that soils with moss and algal crusts have different hydraulic conductivities, which may result in different infiltration and runoff patterns for the two crust types. However, we did not observe the infiltration and runoff for the moss and algal crusts in fixed sand dunes of the Tengger Desert. Using the Limburg Soil Erosion Model, Li et al. (2001) estimated that runoff amount from leeward slopes was double that from windward slopes, which then flowed to and stored in interdune areas. On a lower leeward slope of fixed sand dune revegetated in 1956, we found that a gully was formed on June 29, 2003, following a $57.5 \mathrm{~mm}$ rainfall (Fig. 4). This confirms the prediction from this study that, on the steep leeward slope covered mainly with algal crusts, runoff occurs more easily than on shallow windward slope with moss crusts. Studies from other regions showed that the low water holding capacity of cyanobaterial crusts comparing to moss crusts results

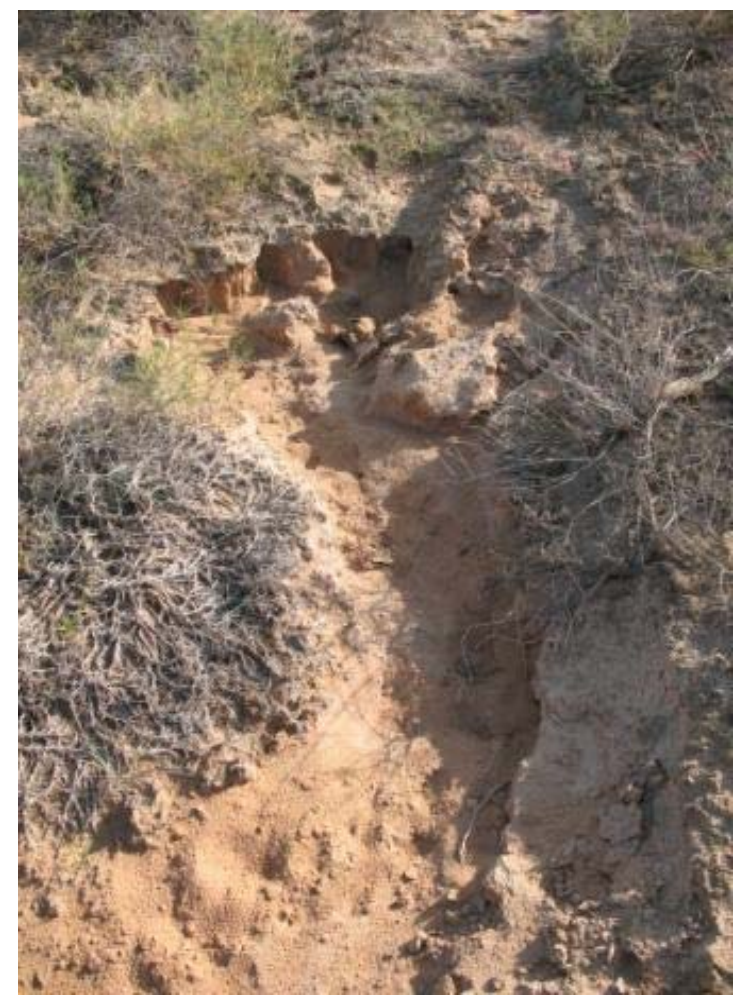

Fig. 4 Photo showing a gully located on the lower leeward of the fixed sand dunes revegetated in 1956 
in low infiltration rate and high frequency and magnitude of runoff, and runoff generated over such crusts infiltrates at a downslope position where infiltration depth is high (Kidron et al., 2003; Almog and Yair, 2007). In comparison with algal crusts, moss crusts have more biologically-derived macrospores (Eldridge et al., 2010), such as ant nests often distribute in interdune of older fixed sand dunes ( $\mathrm{Li}$ et al., 2011), which render moss crusts to keep high infiltration rate and mediate deep soil water (Li et al., 2014). Our current data shed light on the importance of topographic differentiations of BSCs on landscape-scale hydrology in the fixed sand dunes.

The topographic differentiation of BSCs affects not only various hydrological processes, but also influences a number of ecological pattern and processes. Our survey shows that the density and cover of annuals and shrubs on interdunes of fixed sand dunes are higher than those on other sites (Table 1). In addition, with the presence of moss BSCs, the growth of annuals is encouraged more than with the presence of algal BSCs on sand surface due to higher roughness and water-holding capacity of moss crusts. This agrees with former studies in which moss crusts had higher seed entrapment and germination rates, and assured a higher survival rate of annuals than algal crusts ( $\mathrm{Li}$ et al., 2005, 2010; Su et al., 2007). Finally, the topographic differentiations of BSCs not only substantially affect hydrological and ecological processes and result in spatial variability in deep soil water storage and vegetation structure and succession on fixed sand dunes, but also play an important role in other ecological processes, such as those that induce shrub's patchiness at landscape-scale as other regions found (Eldridge et al., 2000, 2002; Maestre et al., 2002; Kidron et al., 2003; Almog and Yair, 2007). We supposed that transition from steep leeward slope to interdune land where easily get additional water supply by runoff generated on leeward slope, is likely to be a suitable place for growth and development of vascular plants. Also, the vegetation patchiness at landscape-scale induced by topographic and hydrological processes would be expected to reinforce, i.e increase in spatial heterogeneity with successions of revegetation-soil system on fixed sand dunes.

\section{Conclusions}

As the limited precipitation in the Tengger Desert is the main water supply for the restored vegetation, hydrological processes and water budgets have significant effects on the ecological patterns and processes (Li et al. 2004; Liu et al. 2006; Wang et al. 2007b; Zhang et al. 2008). The cover, composition and thickness of BSCs and related soil physical and chemical properties have clear topographic dependence and induce variability of surface soil hydraulic properties. In turn, topographic differentiation of surface soil hydraulic properties affects a number of hydrological processes, such as rainfall infiltration, runoff and soil water storage, leading to reduced and heterogeneous deep soil water storage, and increased spatial heterogeneity of vegetation. Thus, we conclude that the BSCs are a major biological driver in the succession of revegetation via their influence on the hydrological processes. Further experiments on the fixed sand dunes are needed to elucidate mechanisms by which BSCs affects infiltration, runoff and soil water storage, and to predict ecological processes under future scenarios of rainfall pattern change.

\section{Acknowledgements}

This research was funded by the National Basic Research Program of China (2013CB429901), the National Natural Science Foundation of China (41471434, 31170385) and the Foundation for Excellent Youth Scholars of CAREERI, Chinese Academy of Sciences. We thank Janet PATTON at North Dakota State University, USA for valuable suggestions that helped improve the manuscript.

\section{References}

Almog R, Yair A. 2007. Negative and positive effects of topsoil biological crusts on water availability along a rainfall gradient in a sandy arid area. Catena, 70: 437-442.

Belnap J. 2006. The potential roles of biological soil crusts in dryland hydrologic cycles. Hydrological Processes, 20: 3159-3178.

Berndtsson R, Chen H S. 1994. Variability of soil water content along a transect in a desert area. Journal of Arid Environments, 27: 127-139.

Brotherson J D, Rushforth S R. 1983. Influence of cryptogamic crusts on moisture relationships of soils in Navaip National Monument. Great Basin Naturalist, 43: 73-78.

Duan Z H, Xiao H L, Li X R, et al. 2004. Evolution of soil properties on stabilized sands in the Tengger Desert, China. Geomorphology, 59: 237-246.

Eldridge D J, Zaady E, Shachak M. 2000. Infiltration through three 
contrasting biological soil crusts in patterned landscapes in the Negev, Israel. Catena, 40: 323-336.

Eldridge D J, Zaady E, Shachak M. 2002. Microphytic crusts, shrub patches and water harvesting in the Negev Desert: the Shikim system. Landscape Ecology, 17: 587-597.

Eldridge D J, Bowker M A, Maestre F T, et al. 2010. Interactive effects of three ecosystem engineers on infiltration in a semi-arid Mediterranean grassland. Ecosystems, 13: 499-510.

FAO/UNESCO. 1974. Soil Map of the World 1:5,000,000. Volume 1. Paris: UNESCO.

George D B, Roundy B A, St. Clair L L, et al. 2003. The effects of microbiotic soil crusts on soil water loss. Arid Land Research and Management, 17: 113-125.

Halbertsma J M, Veerman G J. 1997. Determination of the unsaturated conductivity and water retention characteristics using the Wind's evaporation method. In Stolte J. Manual for Soil Physical Measurements. Wageningen: DLO Winand Staring Centre, 47-55.

Hu C X, Liu Y D, Zhang D L, et al. 2002. Cementing mechanism of algal crusts from desert area. Chinese Science Bulletin, 47: 1361-1368.

Hu W, Shao M A, Wang Q J, et al. 2009. Temporal changes of soil hydraulic properties under different land uses. Geoderma, 149: 355-366.

Kidron G J, Yair A, Vonshak A, et al. 2003. Microbiotic crust control of runoff generation on sand dunes in the Negev Desert. Water Resource Research, 39: 1108-1112.

Kidron G J. 2007. Millimeter-scale microrelief affecting runoff yield over microbiotic crust in the Negev Desert. Catena, 70: 266-273.

Li T, Xiao H L, Li X R. 2001. Modeling the effects of crust on rain infiltration in vegetated sand dunes in arid desert. Arid Land Research and Management, 15: 41-48.

Li X R, Ma F Y, Xiao H L, et al. 2004. Long-term ecosystem effects of vegetation on soil water content of sand dunes in arid region of Northern China. Journal of Arid Environments, 57: 1-16.

Li X R, Jia X H, Long L Q, et al. 2005. Effect of biological soil crusts on seed bank, germination and establishment of two annual plant species in the Tengger Desert (China). Plant and Soil, 27: 375-385.

Li X R, He M Z, Stefan Z, et al. 2010. Micro-geomorphology determines community structure of BSCs at small scale. Earth Surface Processes and Landforms, 35: 932-940.

Li X R, Jia R L, Chen Y W, et al. 2011. Association of ant nests with successional stages of biological soil crusts in the Tengger Desert, Northern China. Applied Soil Ecology, 47: 59-66.

Li X R, GaoY H, Su J Q, et al. 2014. Ants mediate soil water in arid desert ecosystems: Mitigating rainfall interception induced by biological soil crusts? Applied Soil Ecology, 78: 57-64.

Liu L C, Song Y X, Gao Y H, et al. 2007. Effects of microbiotic crusts on evaporation from the revegetated area in a Chinese desert. Australia Journal of Soil Research, 45: 1-6.
Maestre F T, Huesca M T, Zaady E, et al. 2002. Infiltration, penetration resistance and microphytic crust composition in contrasted microsites within a Mediterranean semi-arid steppe. Soil Biology and Biochemistry, 34: 895-898.

Malam I O, Défarge C, Trichet J, et al. 2009. Microbiotic soil crusts in the Sahel of western Niger and their influence on soil porosity and water dynamics. Catena, 77: 48-55.

Mualem Y. 1976. A new model for predicting the hydraulic conductivity of unsaturated porous media. Water Resource Research, 12: 513-522.

Shapotou Desert Research and Experiment Station, Chinese Academy of Sciences. 1991. Study on Shifting Sand Control in Shapotou Region of Tengger Desert (2). Yingchuan: Ningxia People's Press, 101-106. (in Chinese)

Šimûnek J, Wendroth O, van Genuchten M T. 1998. A parameter estimation analysis of the evaporation method for determining soil hydraulic properties. Soil Science Society of America Journal, 62: 894-905.

Su Y G, Li X R, Cheng Y W, et al. 2007. Effects of biological soil crusts on emergence of desert vascular plants in North China. Plant Ecology, 191: 11-19.

van Genuchten M T H. 1980. A close-form equation for predicting the hydraulic conductivity of unsaturated soils. Soil Science Society of America Journal, 44: 892-898.

Wang X P, Li X R, Xiao H L, et al. 2006. Evolutionary characteristics of the artificially revegetated shrub ecosystem in the Tengger Desert, Northern China. Ecological Research, 21: 415-424.

Wang X P, Li X R, Xiao H L, et al. 2007a. Effects of surface characteristics on infiltration patterns in an arid shrub desert. Hydrological Processes, 21: 72-79.

Wang X P, Young H M. Yu Z, et al. 2007b. Long-term effects of restoration on soil hydraulic properties in revegetation stabilized desert ecosystems. Geophysical Research Letters, 34: L24S22.

Warren S D. 2003. Synopsis: influence of biological soil crusts on arid land hydrology and soil stability. In: Belnap J, Lange O L. Biological Soil Crusts: Structure, Function, and Management. Berlin: Springer-Verlag, 349-360.

West N E. 1990. Structure and function of microphytic soil crusts in wildland ecosystems of arid to semi-arid regions. Advances in Ecological Research, 20: 179-223.

Williams J D, Dobrowolski J P, West N E. 1999. Microbiotic crust influence on unsaturated hydraulic conductivity. Arid Soil Research and Rehabilitation, 13: 145-154.

Zhang Y M, Wu N, Zhang B C, et al. 2010. Species composition, distribution patterns and ecological functions of biological soil crusts in the Gurbantunggut Desert. Journal of Arid Land, 2(3): 180-189.

Zhang Z S, Liu L C, Li X R, et al. 2008. Evaporation properties of a revegetated area of the Tengger Desert, North China. Journal of Arid Environments, 72: 964-973. 